\title{
FINDINGS ON THE LOCAL VERSION OF ELSHANSKAYA CULTURE
}

(C) 2016

V.V. Stavitsky, doctor of history sciences, professor of General History, Historiography and Archeology Department Penza State University, Penza (Russia)

Abstract. The article deals with the problem of the local variants allocation of Elhanskaya culture. The question of the local variants allocation was first raised and substantiated in the dissertation of K.M. Andreev. Based on the analysis of ceramic traditions, he distinguished two variants of the Elshanskaya culture: the east and the west. To the east variant he attributed the settlements of Samara-Volga, the Middle Posur and the basin of the Sviyaga, to the west - the settlements of the Upper Primokshanye and Prihoperya. The uniting of elshansky monuments of Samara-Volga and Central Posur seems inappropriate. Pottery from these settlements has a number of significant differences in the ornamentation of the vessels and the technology of preparation of clay dough. By its appearance ceramics of Prisursky settlements are closer to the Antiquities of Primokshanye. Primokshansky settlements materials should be seen as a part of one-time pulse at the end of the VII Millennium BC. The further development of the local population traditions, apparently, was no longer associated with the «classical» antiquities of the Elshanskaya culture. The late materials of the Alatyrsky Posur settlements, related to the mid-VI millennium BC, apparently, should be considered in the context of the cultural tradition of the Lugovoye III - the Krasny gorodok settlements.

Keywords: Elshanskaya culture; early Neolithic; steppe Trans-Volga; Alatyrsky Posure; Upper Primokshanye; Upper Prihoperie; local variant; ceramic tradition; cultural momentum; infiltration; Neolithic settlements; ornamental motifs; social networks.

\section{ДРЕВНЕЙШИЕ ПОСТРОЙКИ КАМЕННОГО ВЕКА НА ТЕРРИТОРИИ СМОЛЕНСКОЙ И ПСКОВСКОЙ ОБЛАСТЕЙ РОССИИ}

И.Ю. Хрусталева, младший научный сотрудник отдела археологии Восточной Европы и Сибири Государственный Эрмитаж, Санкт-Петербург (Россия)

Аннотация. Работа посвящена анализу древнейших домостроительных традиций верховий р. Западная Двина. В статье рассматриваются самые ранние постройки этого региона, зафиксированные на материковом слое базовых сезонных поселений каменного века Смоленской и Псковской областей: Сертея 3-3, Сертея X, Сертея XIV, Рудня Сертейская и селище Узмень. В процессе раскопок эти материалы были выделены в единый ранненеолитических пласт с керамикой сертейской культуры. В результате анализа пространственного расположения остатков построек на площади поселений Сертея X, Сертея XIV, а также после изучения находок, связанных с этими конструкциями, удалось выделить и обосновать наличие внутри этого горизонта мезолитических построек. Анализ планов и остатков конструкций построек позволил выявить особенности перехода от мезолита к раннему неолиту, проявляющиеся в изменении формы построек: переходе от округлых в плане конструкций к овальным и подпрямоугольным, что также отмечается многими исследователями каменного века, причем не только для территорий лесной зоны. Такие изменения вряд ли являются случайными и, вероятно, могут рассматриваться как некий элемент процесса неолитизации, но эти предположения еще требуют дополнительных разработок и доказательств.

Ключевые слова: мезолит; ранний неолит; культура сертейской ранненеолитической керамики; СевероЗапад России; Смоленская область; Псковская область; жилища; постройки; неолитизация; сезонные поселения; стоянки; поселения в песчаных отложениях; относительная хронология.

В традиционном обществе жилище является не просто объектом материальной культуры, оно отражает все грани мировоззрения его обитателей, «это один из ключевых символов культуры...» [1]. Но при исследовании археологических памятников мы имеем дело в основном только с материальной составляющей культуры, причем в трансформированном в результате процесса археологизации виде. Ограничения в выборе вариантов конструкций жилища вносит его назначение (защита от воздействий окружающей среды), а также технические возможности строителей [2]. Выявление остатков постройки на археологическом памятнике может представлять собой довольно сложную задачу, и для ее решения необходимо определить набор признаков, по которым можно выделить остатки сооружения. К первому признаку относятся структуры, которые можно определить как участки куль- турного слоя, отличные от окружающего пространства. Отличия могут заключаться в иной окраске культурного слоя; в наличии костных, каменных, деревянных развалов, тлена, которые подчинены какойлибо закономерности. Одним из «атрибутов» жилища, хотя и необязательным, называют остатки очагов и кострищ. Реже индикатором несохранившейся постройки является специфический набор инвентаря. Но важно учитывать, что более темное пятно культурного слоя может быть объяснено природными (химическими) процессами, зольными и углистыми остатками выбросов из очага, сгоревшего жилища, обгоревшей корневой системы деревьев [3, с. 20-22]. Особую сложность вызывает выявление остатков построек на памятниках, культурные слои которых залегают в песках и супесях, поскольку в таких условиях не сохраняются органические материалы. К такой катего- 
рии стоянок относится большинство памятников каменного века Смоленской и Псковской областей, о которых и пойдет речь ниже.

Активные археологические изыскания на территории Смоленской и Псковской областей начали проводиться с 60-х гг. ХХ в. Невельской (впоследствии Северо-Западной) экспедицией Государственного Эрмитажа под руководством А.М. Микляева, а затем А.Н. Мазуркевича $[4 ; 5 ; 6]$. К настоящему времени открыто уже более сотни стоянок каменного века. В число этих стоянок входит ряд памятников с остатками разновременных жилищ, хозяйственных сооружений и очагов с большим количеством кремневых и керамических находок. Это памятники Сертея 3-3, Сертея X, Сертея XIV, Рудня Сертейская, селище Уз- мень (рис. 1). Они интерпретируются как долговременные базовые сезонные поселения, объекты и находки которых датируются временем от мезолита до позднего неолита/энеолита [7; 8]. В общей сложности на этих поселениях можно выделить остатки порядка 35 построек, различных по конструкциям, назначениям и по времени бытования. Отдельно стоит упомянуть об открытых в этом регионе поздненеолитических свайных поселениях Сертея II, Дубокрай IV, Наумово, Усвяты II-VII и др. [9; 10; 11 и т.д.]. В связи со значительным количеством накопленного материала по постройкам, появилась возможность систематизировать имеющиеся данные и, как следствие, разработать типологию и хронологию объектов.

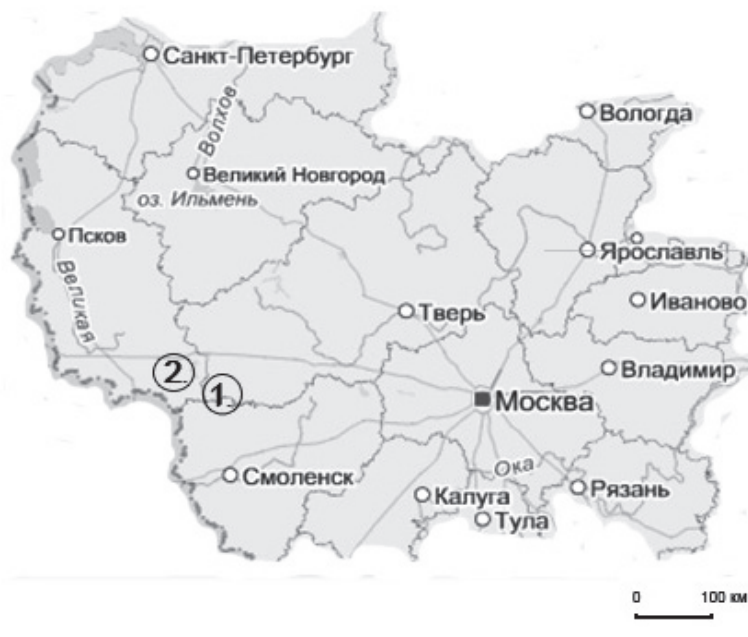

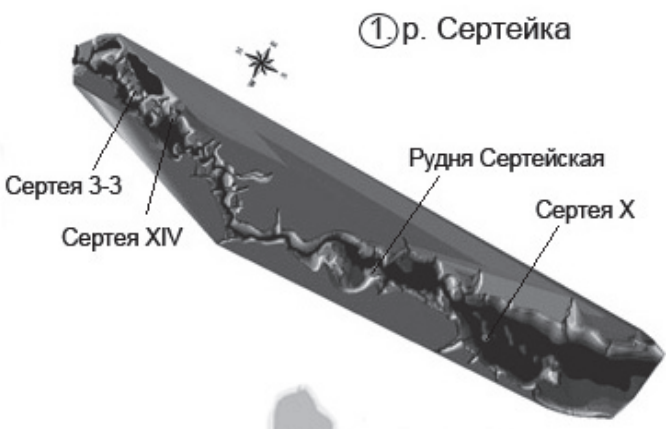

(2.) оз. Узмень

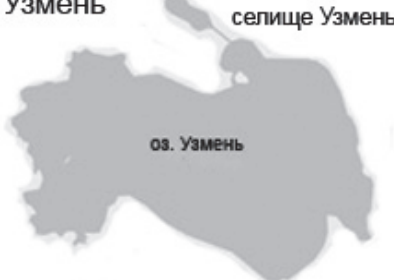

Рисунок 1 - Расположение поселений с остатками построек мезолита - раннего неолита [по: 12 fig. 2 с дополнениями]

Часть найденных памятников располагается на флювиогляциальных (Сертея XIV, 3-3, Рудня Сертейская) отложениях в зоне распространения холмистоморенных и камовых ландшафтов [13, с. 122]. Памятник Сертея X и селище Узмень приурочены к границе флювиогляциальных и моренных отложений. Памятники Сертея 3-3 и Сертея XIV были расположены на различных формах рельефа на северо-восточном берегу древней большой Нивниковской озерной котловины, которую унаследовала р. Сертейка в своем течении к р. Западная Двина, на расстоянии ок. 600 м друг от друга. Поселение Сертея 3-3 находилось на небольшой площадке у края высокой террасы и было окружено небольшими камовыми останцами. Оно возвышалось над зеркалом палеоводоемов на 15-17 м [14]. В то время как поселение Сертея XIV располагалось на пологом склоне террасы в непосредственной близости от воды. Поселение Сертея X находилось на суходоле, который входил в цепочку суходолов, протянувшихся с севера на юг в торфянике Сертейской озерной котловины. По отношению к старице р. Сертейки они образовывали правый берег. Ныне суходолы находятся на левобережье магистрального канала, в который заключена р. Сертейка [15]. Стоянка была расположена на западной оконечности суходола, обращенного к старице реки Сертейки [16]. Селище Узмень располагалось у борта Узменьской озерной кот- ловин. Памятник Рудня Сертейская находился на небольшом мысу, вдающемся в Руднянскую озерную котловину, на погребенной озерно-болотными отложениями террасе [17].

Культурные слои памятников в большинстве своем залегали в минеральных береговых отложениях, а на поселениях Сертея X и Сертея XIV они частично переходили и в толщу озерно-болотных отложений. Стратиграфия поселений, расположенных на песчаных берегах, в целом сходна: верхний слой дерна и оторфованной почвы представляет собой пахоту на поселениях Сертея 3-3 и Сертея Х. Ниже следовали слои желтых и серых песков и супесей. Материк представлен светло-желтым пылеватым песком, а на поселении Сертея X - красной глиной, замещающейся слоем алеврита в торфяниковой части $[18$, с. 6]. Культурные слои «А» стоянки Рудня Сертейская с находками раннего неолита относятся к прослойке мелкого и пылеватого песка в основании толщи сапропелевых отложений, перекрытых слоями суглинка и торфа. Ниже залегали алевриты, перекрывавшие мелкозернистый пылеватый светлый песок [17]. Культурные слои селища Узмень залегали в отложениях гумусированного песка и были сильно повреждены распашкой [19].

Определенного окраса культурные слои памятников не имели и соответствовали цвету вмещавших их 
литологических слоев - песка или супеси, что не давало стратиграфического обоснования расчленения на культурные горизонты [20]. Поскольку процесс почвообразования в песке происходит очень медленно, а между горизонтами не было стерильных прослоек, то весь материал залегал практически единым массивом. В процессе раскопок остатки построек на поселениях выделялись только по незначительным западинам культурного слоя, в тех случаях, когда они были, по столбовым ямам и укрепляющим их конструкциям, камням или песчаным выбросам. Причем во многих случаях столбовые ямы удавалось зафиксировать только на уровне материка. Заполнение ям столбовых и кольевых ям, а также жилищных западин выделялось более темным окрасом на общем фоне вмещающего культурного слоя. Очаги и кострища удалось обнаружить благодаря их конструкциям (например, каменным обкладкам), если таковые имелись, и по прокаленному песку, отличавшемуся красноватым оттенком, либо по серой зольной прослойке (согласно полевой документации). Кроме того, на поселениях Сертея X, Сертея 3-3 и частично Сертея XIV отбирались пробы для геохимических анализов, и выявленные остатки построек были верифицированы особенностями распределения фосфатов в культурном слое $[21 ; 22]$.

Еще на этапе полевых работ исследователями было установлено, что эти стоянки содержат разновременный материал от мезолита до позднего неолита с остатками разнообразных жилых и хозяйственных ям и конструкций. Дальнейшие работы по пространственному анализу объектов и типов находок с применением компьютерного трехмерного моделирования (работы проводились А.Н. Мазуркевичем, М.Э. Полковниковой, Д.В. Герасимовым, Е.В. Долбуновой) дали возможность выделить разновременные «горизонты обитания» на поселениях [23; 24; 25]. Не все сооружения были выделены сразу на этапе раскопок, часть из них (не имевшая четко выраженного контура пола или жилищной западины) была определена А.Н. Мазуркевичем уже в процессе обработки полевой документации по высотным отметкам столбовых и кольевых ям, с этим связана их нумерация по входящим в их конструкцию ямам.

Рассматриваемые памятники предоставляют уникальную возможность для анализа изменений домостроительных традиций каменного века региона в долговременной перспективе. В настоящей работе невозможно охватить весь массив данных по всем постройкам региона, поэтому на данном этапе наше внимание сосредоточено только на самых первых (нижних) «горизонтах обитания». В ходе работы были проанализированы форма, размеры и особенности конструкций построек, их пространственное расположение на площади памятников. Были проанализированы находки, связанные с этими постройками, что дало основания для выводов об их относительной хронологии. Ниже представлены предварительные результаты проведенного исследования.

Самые ранние остатки построек на стоянках были выявлены на светло-желтом пылеватом материковом песке, образовавшемся в бореальное время [24]. Поскольку между разновременными горизонтами поселений нет стерильных прослоек, то самый ранний этап обитания включает в себя находки периода от 9,3 тыс. некалиброванных радиоуглеродных л. н. (время образования материкового песка) до 7 тыс. некалиброванных радиоуглеродных л. н. (период мощной трансгрессии и образования слоя светло-желтой супеси) [26; 27]. Радиоуглеродных датировок для самих комплексов практически нет, поскольку никакие органические материалы в песчаных отложениях не сохранились, и нет датирующего материала. Тем не менее, есть несколько дат по нагару с ранненеолитической керамики сертейской культуры, найденной в самых нижних горизонтах поселений: Рудня Сертейская

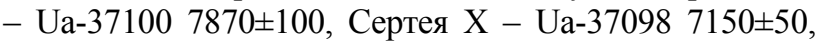
Сертея XIV - Ua-37099 $8380 \pm 55$. Но стоит учитывать влияние на эти даты резервуарного эффекта [28]. В целом, появление здесь керамики сертейской культуры относится к периоду около 6200 кал. лет до н.э. [27].

На поселении Сертея 3-3 к этому периоду относится система из трех округлых конструкций № 19, 20 и 26 [14]. Западина № 20 - пол несохранившейся постройки - имела округлую форму и была углублена в материк в среднем на 0,11-0,16 м, d (здесь и далее диаметр) 4,5 м. У восточной и западной стен западины, а также в центре были зафиксированы столбовые ямы. В западной части постройки, у «стены» располагалась овальная очажная яма $1,5 \times 1,3$ м, глубиной 0,56 м. Внутри сооружения, по ее периметру был небольшой песчаный валик высотой около 0,03-0,07 м. В постройке № 20 было зафиксировано два «перехода» к двум другим постройкам (в северное сооружение № 19 и в южное - № 26). Эти переходы представляли собой небольшие углубленные на $0,1-0,15$ м в материк «коридоры» шириной от 0,4 до 0,9 м. В южной части постройки № 20 было обнаружено скопление кремневых отщепов, сколов, нуклеусов, отбойник и фрагменты сосудов ранненеолитической сертейской культуры фазы «b». Постройка № 19 в плане имела неправильную подовальную форму размерами 4,1×3,4 м. Постройка № 26 неправильной округлой формы имела d 2 м, в материк она была углублена примерно на 0,14 м в южной части и на 0,3 м - в северной. Внутри западины были выделены три столбовые ямы.

На материковом песке поселения Сертея XIV были выявлены два округлых жилища № № 558 и 562 и одно подпрямоугольное - № 15 [согласно полевым чертежам, по: 29, 30, 31].

1. Остатки постройки № 558 с углубленным очагом в северо-восточной части представляли собой округлое углубление размером $3,08 \times 2,3$ м $\left(\mathrm{S}=5,6 \mathrm{~m}^{2}\right)$ со столбовыми и кольевыми ямами по периметру и центральной столбовой ямой. В заполнении постройки, у ее западной стенки и в центре, были найдены кремневые пластины и несколько сколов.

2. В южной части раскопа была открыта северная часть постройки № 562 округлой формы d порядка 6 м $\left(\mathrm{S} \approx 28 \mathrm{~m}^{2}\right)$. По периметру и в центре прослеживались столбовые и кольевые ямы, в северной части конструкции - очажное пятно размерами 0,96×1,20 м. В заполнении самой постройки найдено несколько кремневых пластин, один листовидный наконечник и скребок на отщепе. Довольно сложно что-то говорить об этой постройке, поскольку вскрыта раскопом она лишь частично. Ее остатки были сильно размыты во 
время трансгрессии водоема, контуры ее прослеживались слабо.

3. Постройка № 15 имела размеры $5,2 \times 2,2 \mathrm{M}$ $\left(\mathrm{S}=11,4 \mathrm{~m}^{2}\right)$. Она представляла собой двухступенчатую площадку подпрямоугольной формы, ориентированную с севера на юг, углубленную на 0,1-0,12 м в материк, с плоским дном, имеющим уклон в Ю3 направлении. В центре прослеживались три столбовые ямы и очаг грушевидной формы. В заполнении жилищной западины были найдены кремневые сколы и отщепы, нож, скребок, пластина с ретушью, фрагменты наконечников, а также фрагменты стенок сосудов ранненеолитической сертейской культуры фазы «а». В западной стенке конструкции располагался коридорообразный вход [25].

На поселении Сертея X к этому горизонту относятся постройки № 751, № 7 овальной и подтреугольной формы, сооружения № 977, № 614-615, № 3 и № 608, открытый углубленный овальный очаг № 882 и подковообразная в плане яма № 12 [32; 33].

1. Остатки подпрямоугольного сооружения № 977 представляли собой западину с отвесными стенками и плоским дном размером 3,6×2 м $\left(\mathrm{S}=7,2 \mathrm{~m}^{2}\right)$, углубленную в материк в среднем на 0,05 м [15] по периметру располагались кольевые и столбовые ямы. В центре постройки находился большой углубленный очаг $\mathrm{d}$ 1,28 м. В заполнении постройки у западной и восточной стенок были выявлены фрагменты сосудов ранненеолитической сертейской культуры фазы «b».

2. Остатки постройки № 751 представляли собой западину неправильной овальной формы размерами $2,86 \times 2,14 \mathrm{M}\left(\mathrm{S}=9,3 \mathrm{M}^{2}\right)$ с пологими стенками и ступенчатым округлым дном глубиной 0,2-0,3 м. По периметру были кольевые ямы, в центре располагался округлый очаг [15; 32]. На полу постройки была выявлена керамика ранненеолитической сертейской культуры фазы «b».

3. Сооружение № 614-615 овальной формы размерами $3,6 \times 2,8$ м $\left(\mathrm{S}=10,8 \mathrm{M}^{2}\right)$, представлено кольевыми ямками, расположенными по его периметру. Через центр постройки параллельно длинной оси проходил ряд кольевых ям. В северной части постройки у стены были найдены фрагменты сосудов ранненеолитической сертейской культуры фазы «b».

4. Сооружение № 3 подтреугольной формы размерами $2,8 \times 3,2$ м $\left(\mathrm{S}=3,8 \mathrm{~m}^{2}\right)$ было углублено на 0,50,7 м. В северо-восточной части постройки был округлый углубленный очаг диаметром 0,5 м. Внутри сооружения находились столбовые ямы. К этой постройке относились фрагменты керамических сосудов ранненеолитической сертейской культуры фазы «а» и «b», кремневые отщепы, скребки на отщепах и обломок нуклеуса.

5. Остатки сооружения № 7 округлой формы $\mathrm{d}$ 3,2 м $\left(\mathrm{S}=8 \mathrm{M}^{2}\right)$ представляло собой западину со ступенчатым дном, углубленным в материк на 0,2-0,25 м северной части и на 0,5 м у восточной стенки. По периметру сооружения и в центре были столбовые ямы. В заполнении пола постройки были найдены кремневые пластины и орудия на них, фрагменты наконечников, отщепы, обломки нуклеусов, керамического материала зафиксировано не было.

6. Остатки конструкции № 608, представляли собой прямоугольную наземную конструкцию размерами примерно $3 \times 5$ м $\left(\mathrm{S}=15 \mathrm{M}^{2}\right)$ с большим овальным очагом размерами $1,6 \times 1,4$ м в центре, отгороженным от основного помещения рядом кольев овальную яму, окруженную столбовыми и кольевыми ямами. К СВ и Ю3 сторонам от очага тяготела керамика ранненеолитической сертейской культуры фазы «b».

На материковом песке стоянки Рудня Сертейская были выявлены остатки сильно размытой подпрямоугольной постройки с углубленным полом. С ней соотносится керамика ранненеолитической сертейской культуры фазы «а» [34; 17]. На селище Узмень в 1967 году было открыто $(2,63 \times 1,62$ м) углубленное жилище, имевшее первоначально прямоугольную форму, но в процессе археологизации сохранившееся только в виде овальной в плане ямы. Оно связано с керамикой ранненеолитической сертейской культуры фазы «b» [35].

Анализ находок из построек показал, что в сооружениях № 7 поселения Сертея Х и № 558 и 562 поселения Сертея XIV не было керамики, а кремневый материал имел мезолитический облик. Остальные же постройки всех поселений имеют четкую связь с глиняной посудой ранненеолитической сертейской культуры фаз «a-b» [36; 37].

Пространственный анализ расположения самих построек на поселении Сертея XIV четко указывает на разновременность существования конструкций № 15 и № 558 и 562. Эти сооружения имеют различную топографическую привязку, расположены на разных озерных террасах, что является следствием переноса поселения в начале раннего неолита выше по береговому склону вследствие повышения уровня воды в этот период.

На поселении Сертея X постройка № 7 была расположена на низком берегу, в то время как все конструкции и объекты с керамикой раннего неолита сосредоточены на макушке камового останца. Важно здесь также отметить и стратиграфическое положение этой постройки: ее северная часть была поочередно перекрыта и частично прорезана двумя конструкциями среднего неолита [38], появившимися здесь после понижения уровня воды.

Такие данные позволяют выделить два этапа существования построек на поселениях.

1 эman. К наиболее ранним в данном регионе относятся остатки двух округлых построек (№ 558 и № 562) с поселения Сертея XIV и одной постройки (№ 7) округлой формы с поселения Сертея X (рис. 2). Они были «замыты» трансгрессией, произошедшей 7,5 тыс. некал. С14 л. н., л. н., и, по всей видимости, могут относиться к эпохе мезолита, но основным аргументом в пользу этого предположения служит отсутствие керамических находок.

2 этап. В трансгрессивную фазу водоемов появляются постройки второго этапа. На поселении Сертея XIV это остатки подпрямоугольного в плане жилища № 15 (рис. 3, 1). На поселении Сертея X - сооружения подпрямоугольной и овальной в плане формы № 977, № 614-615, № 608, 751, и подтреугольной - № 3 (рис. 3,$2 ; 4)$. К этому же периоду относятся остатки подпрямоугольных в плане построек со стоянки Рудня Сертейская и селища Узмень (рис. 3, 3). На поселении Сертея 3-3 это система из трех округлых конструкций № 19, 20 и 26 (рис. 5). Эти сооружения относятся к раннему неолиту $(7,5-$ 7 тыс. некалиброванных радиоуглеродных л.н.) с керамикой сертейской культуры фазы «а» и «b». 
<smiles>C1CC1</smiles>
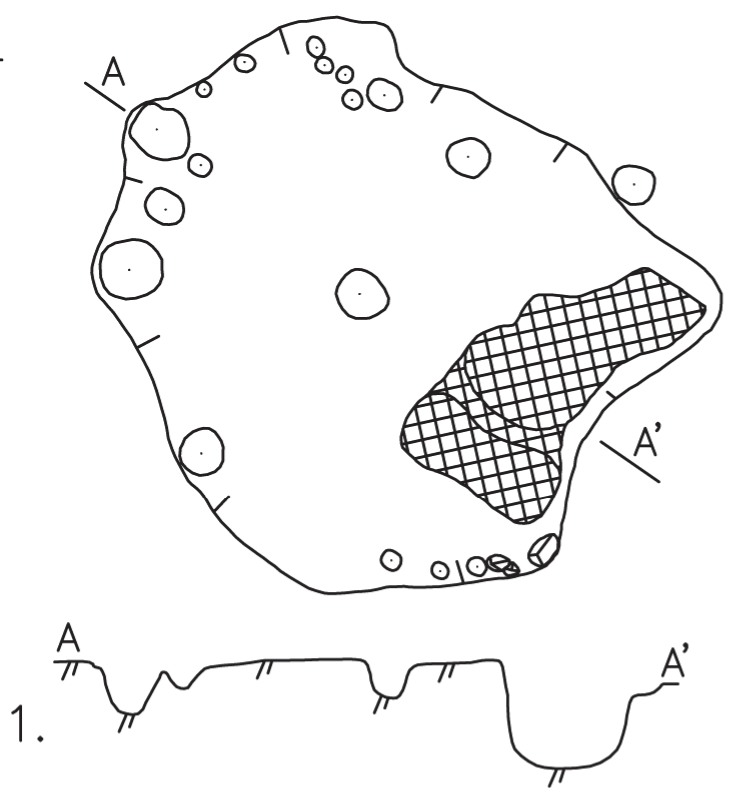

Условные обозначения:
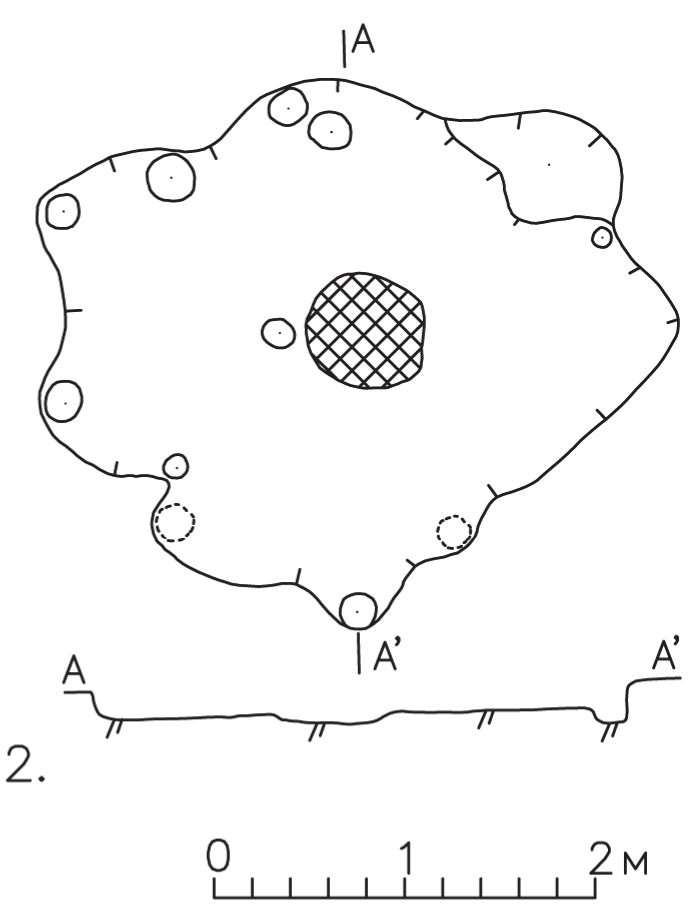

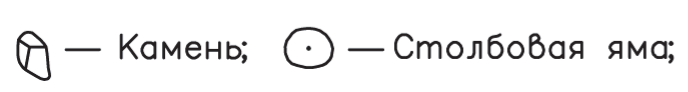

- Очажная яма; 0 - Преgnолагаемая

Рисунок 2 - Контуры и профили мезолитических построек. столбовая яма

1 - Постройка № 558, Сертея XIV. 2 - Постройка № 7, Сертея X [по: 31, 38]

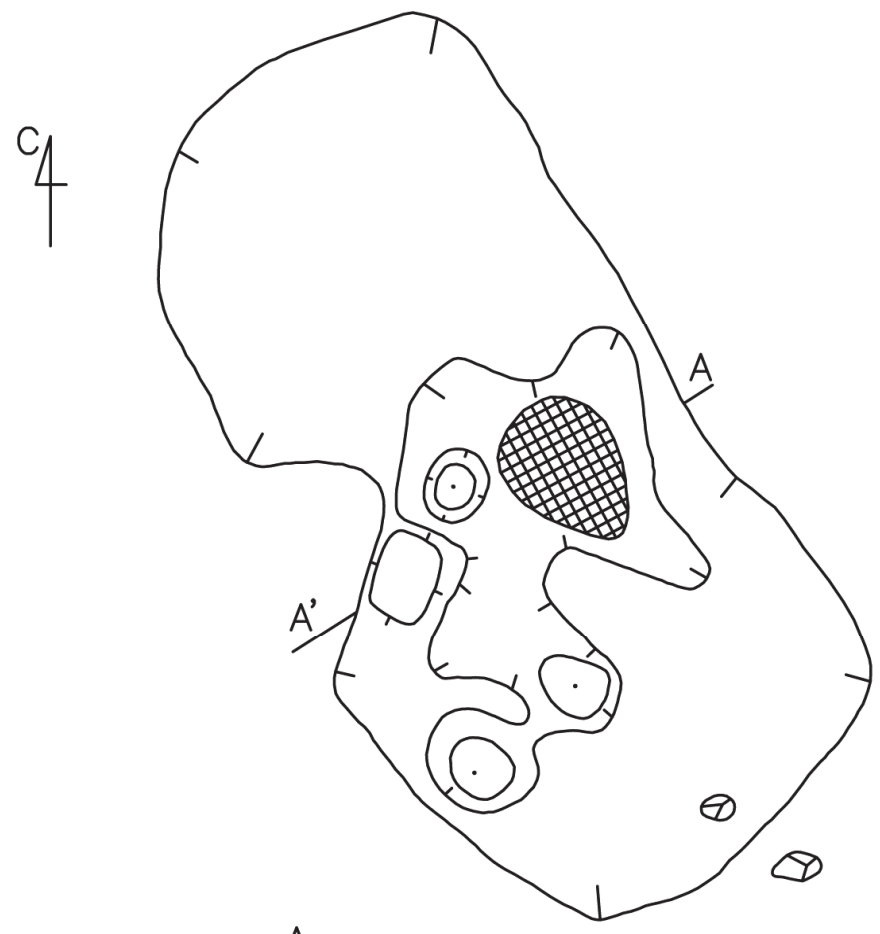

1. $\overbrace{\pi}^{A} \underbrace{A}_{\pi}$

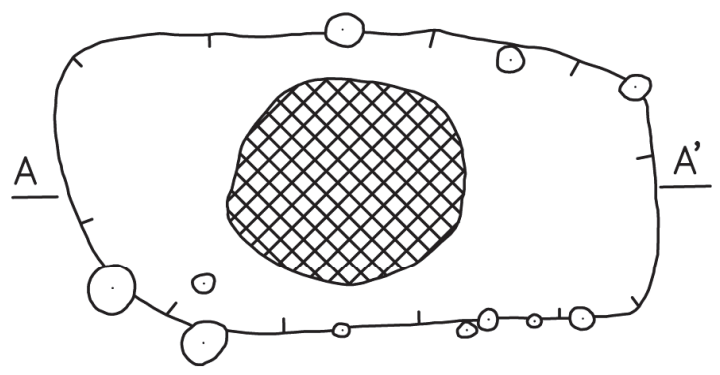

2.

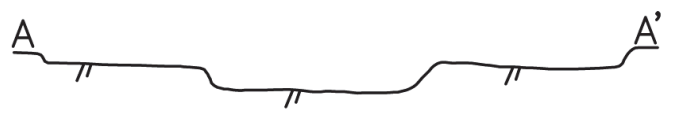

Условные обозначения:

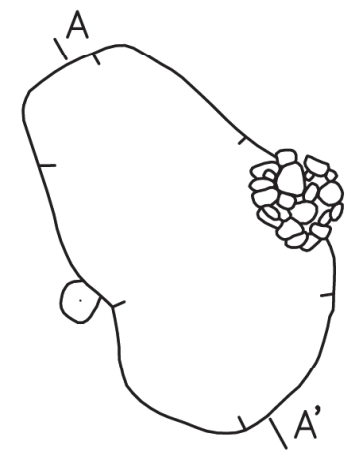

3.

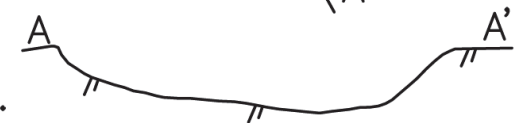

( - Камень;

- Столбовая яма;
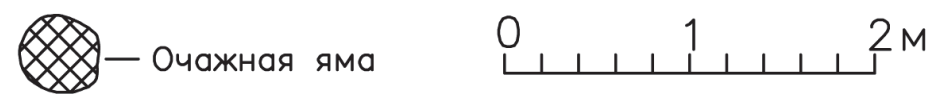

Рисунок 3 - Контуры и профили построек раннего неолита.

1 - Постройка № 15 [по: 25, рис. 2], Сертея XIV.

2 - Постройка № 977, Сертея X [по: 32; 33].

3 - селище Узмень [по: 19, рис. 1] 


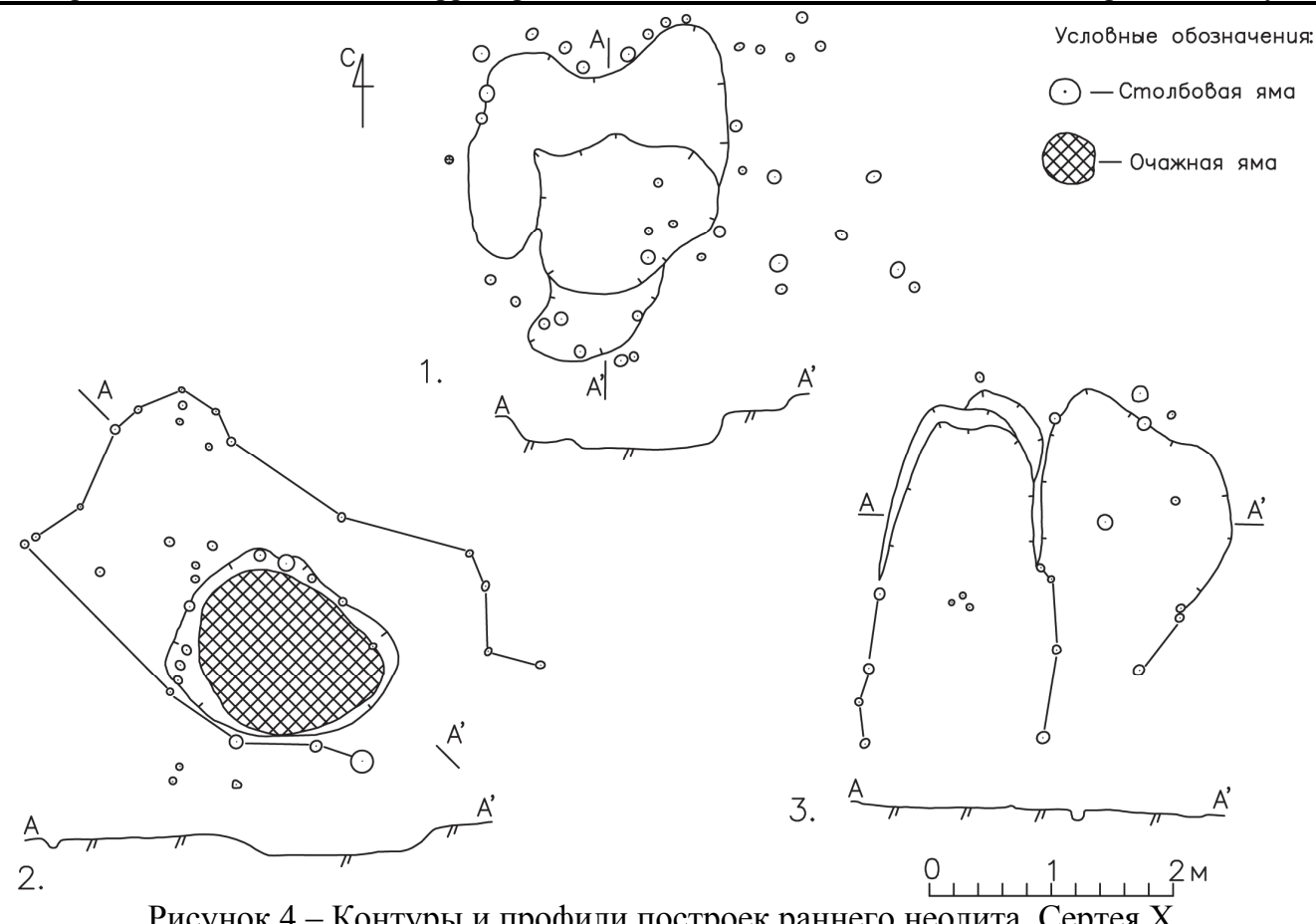

Рисунок 4 - Контуры и профили построек раннего неолита, Сертея X.

1 - Постройка № 751. 2 - Постройка № 608. 3 - Постройка № 614-615 [по: 15; 32]

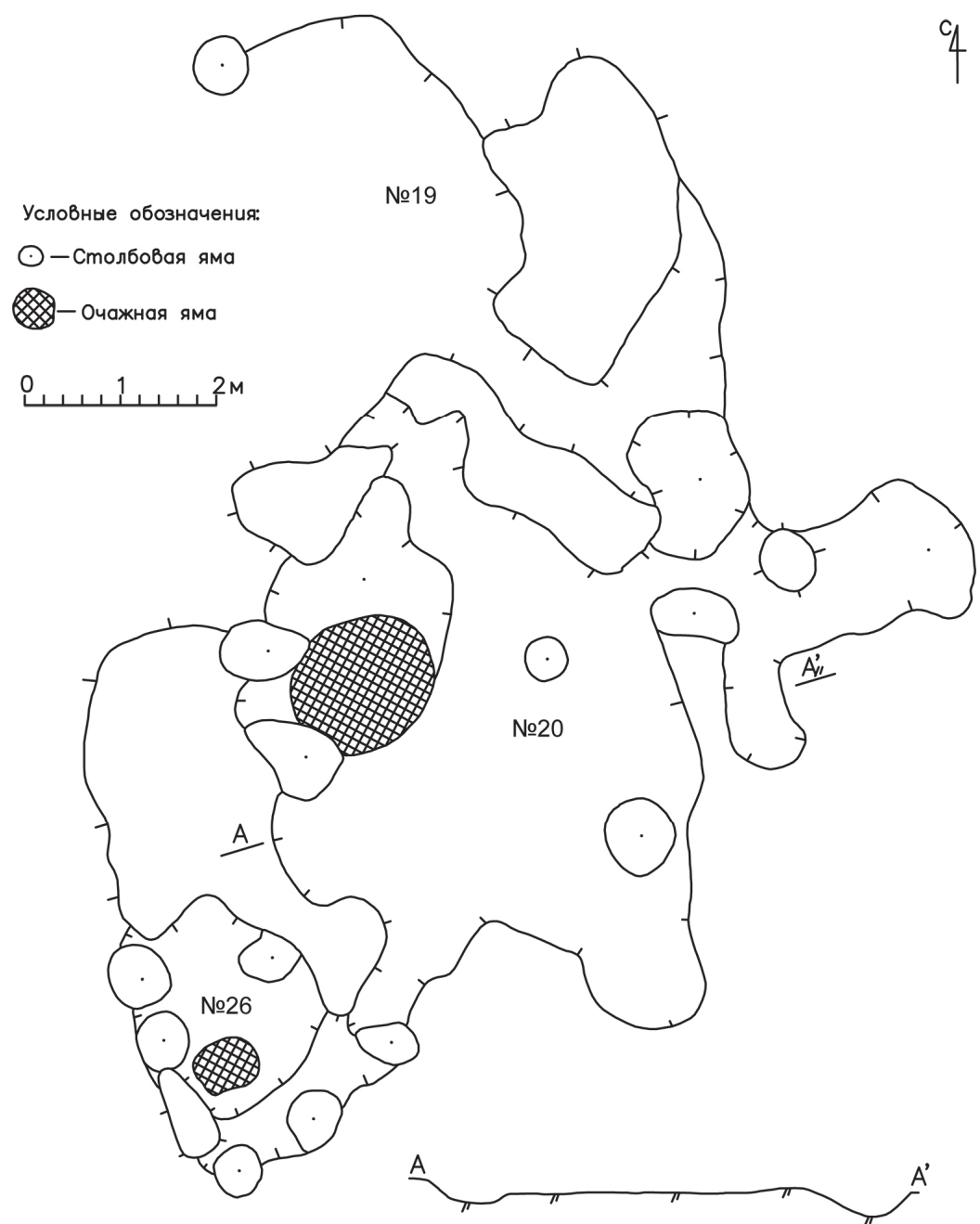

Рисунок 5 - Сертея 3-3. Контуры и профиль построек № 19, 20 и 26 [по: 14, рис. 3]

Таким образом, несмотря на то, что исследователями этих стоянок и ранее упоминалось о наличии мезолитического материала на этих поселениях Сертея X и XIV [5; 7; 8; 25; 26], в работе удалось обосновать выделение мезолитического горизонта с остат- ками построек на памятниках. Наиболее важным наблюдением является тот факт, что мы фиксируем смену форм и конструкций построек на этапе перехода от мезолита к раннему неолиту. На памятниках Сертея X и XIV на смену округлым мезолитическим 
жилищам в раннем неолите появляются подпрямоугольные и овальные в плане конструкции. Такие же сооружения выявлены и на поселениях раннего неолита Рудня Сертейская и селище Узмень. Особняком здесь стоит ранненеолитическое поселение Сертея 3-3 с системой из округлых построек, соединенных переходами. Важно отметить тот факт, что рассматриваемые поселения являются сезонными, и, вероятнее всего, особенности конструкции постройки на поселении Сертея 3-3 связаны с тем, она функционировала в зимний период [39], в то время как поселения Сертея X и XIV, Рудня Сертейская и селище Узмень были летними базовыми лагерями. К сожалению, не так часто нам удается с какой-то долей достоверности установить сезон бытования поселения, особенно при отсутствии остеологического материала среди находок. Этим усложняется поиск аналогий и правомерное сопоставление данных по разным регионам между собой.

Тем не менее следует отметить, что переход от округлых форм жилых сооружений к прямоугольным на этапе перехода от мезолита к раннему неолиту отмечается исследователями в разных регионах: на территории Венгрии [40, fig.7] и в Скандинавских странах [41], на Ближнем Востоке [42; 43, fig. 2; 44, fig. 2] и в Японии [45, fig 6.12]. Хотя материалы по лесной зоне менее красноречивы, здесь также можно отметить изменение форм конструкций на этапе перехода от мезолита к раннему неолиту.

Сложно на данном этапе достоверно установить природу этих изменений и их причины, для этого необходимо проведение отдельного исследования. В качестве основной причины рассматривается, в первую очередь, переход к оседлому образу жизни, необходимость увеличения жилого пространства и более компактной организации поселения вследствие увеличения семьи, проживающей в одном доме (прямоугольная постройка может иметь гораздо бо́льшую площадь, чем округлая, легко решая при этом проблему перекрытия крыши и деления внутреннего пространства); роста самого поселения (прямоугольные постройки легче состыковать и пристроить друг к другу, образуя компактное поселение) [46; 42]. Локально могли влиять и изменения природно-климатической обстановки, природно-географические и экологические факторы, но вряд ли может объяснить изменения на столь обширной территории. Особенно важно отметить, что этот переход происходит вне зависимости от типов используемых строительных материалов (поскольку это происходит и на поселениях с деревянными столбовыми конструкциями, и с каменными) и особенностей обустройства пола (трансформация коснулась как наземных, так и заглубленных сооружений). Говорить о существенном увеличении размеров площади построек при этом не приходится, это дает основания полагать, что основная идея таких трансформаций заключалась именно в изменении формы сооружения. Стоит подчеркнуть, что речь идет именно о стационарных постройках на долговременных поселениях.

В целом, процесс перехода от мезолита к неолиту является одним из наиболее дискуссионных вопросов археологии каменного века Евразии [47; 48; 49; 50 и т.д.]. Большой массив научной литературы охватыва- ет различные аспекты процесса неолитизации, в первую очередь появления и распространения керамики, производящего хозяйства, и в целом внедрения «неолитического образа жизни» ('neolithic way of life') [49; 51]. Понятно, что нельзя упускать из внимания и другие не менее важные и заметные процессы, происходившие в это время [48; 50; 52 и др.]. Они касаются расширения контактов, изменений во взаимодействии человека с окружающей средой, в системе расселения: появились большие стационарные поселения с жилыми и хозяйственными структурами, что может быть связано с переходом к большей оседлости и с некой переориентацией древнего населения на водные пищевые ресурсы [52; 53], а также изменении форм и размеров жилищ $[42 ; 43 ; 40 ; 41 ; 44]$. Поэтому стоит внимательнее присмотреться к этому аспекту материальной культуры древнего населения. Ведь те глобальные изменения, которые произошли в жизни человеческих коллективов в этот период, очевидны, а жилище, помимо всего прочего, является прямым отражением всех особенностей как хозяйственной, так и духовной жизни его обитателей.

\section{СПИСОК ЛИТЕРАТУРЫ:}

1. Байбурин А.К. Жилище в обрядах и представлениях восточных славян. М., 2005.

2. Сидоров В.В. Волосовские жилища поселений Маслова Болота // Тверской археологический сборник. Вып 5. 2002. С. 348-362.

3. Жульников А.М. Древние жилища Карелии. Петрозаводск: «Скандинавия», 2003. 200 с.

4. Микляев А.М. Памятники Усвятского микрорайона. Псковская область // Археологический сборник Государственного Эрмитажа. № 11. Л., 1969. C. $18-40$.

5. Mazurkevich A., Kulkova M., Savel'eva L. Human occupation history of the Upper Dvina basin // Geoarchaeological issues of the Upper Dnieper - Western Dvina river region (Western Russia): Fieldtrip Guide. Moscow-Smolensk: Universum, 2012. P. 70-104.

6. Мазуркевич А.Н. Северо-Западная археологическая экспедиция // Экспедиции. Археология в Эрмитаже. СПб: «Славия», 2014. С. 28-45.

7. Микляев А.М., Еремеев И.И., Короткевич Б.С., Мазуркевич А.Н. Работы Северо-Западной экспедиции Гос. Эрмитажа в 1991 году // Отчетная археологическая сессия. Краткие тезисы докладов. СПб., 1992. C. 3.

8. Микляев А.М., Короткевич Б.С., Мазуркевич А.Н. О работе Северо-Западной археологической экспедиции Государственного Эрмитажа в 1992 году // Отчетная археологическая сессия. Тезисы докладов. СПб, 1993. С. 3.

9. Микляев А.М. Неолитическоео Свайное поселение на Усвятском озере // Археологический сборник Государственного Эрмитажа. № 13. Л., 1971. С. 7-29.

10. Семенов В.А. Свайные поселения бассейна Западной Двины III-II тыс до н.э. как исторический источник. автореф. дис.... канд. ист. наук. Л., 1979.

11. Мазуркевич А.Н. Свайные поселения СевероЗапада России // Археология озерных поселений IV-II тыс до н.э.: хронология культур и природно-климатические ритмы. СПб: Периферия, 2014. С. 260-266.

12. Mazurkevich A., Dolukhanov P., Shukurov A., Zaitseva G. Late stone - early bronze sites age in the 
Western Dvina-Lovat area // The East European Plane on the Eve of Agriculture. BAR International Series 1964. Oxford, 2009. P. 145-153.

13. Санько А.Ф. Неоплейстоцен Северо-Восточной Белоруссии и смежных районов РСФСР. Минск: Наука и техника, 1987. 178 с.

14. Мазуркевич А.Н., Полковникова М.Э. Особенности пространственной организации памятника Сертея 3 (Велижский район Смоленской области) // Acta archaeologica Albaruthenica. Vol. III // Мінск. 2008. C. 104-117.

15. Мазуркевич А.Н. Отчет о работе СевероЗападной археологической экспедиции в 1998 году. НА ИА РАН. Ф. 1. Р. 1. ОП. 1. № 24298. СПб., 1999.

16. Мазуркевич А.Н., Еремеев И.И., Короткевич Б.С., Фурасьев А.Г. Исследования СЗАЭ в Псковской и Смоленской областях в 1998 г. СПб., 1999. С. 3-8.

17. Мазуркевич А.Н., Микляев А.М. О раннем неолите междуречья Ловати и Западной Двины // Apхеологический сборник Государственного Эрмитажа. № 33. СПб., 1998. С. 7-32.

18. Мазуркевич А.Н. Отчет о работе Северо-Западной археологической экспедиции в 1994 году. НА ИА РАН. Ф. 1. Р. 1. № 19890. СПб., 1995.

19. Минасян Р.С. Поселение и могильник на берегу озера Узмень // Труды Государственного Эрмитажа. Т. ХХ. Л.: Икусство, 1979. С. 169-185.

20. Полковникова М.Э. О месте памятников Сертея XII и Сертея XIV в неолите Ловатско-Двинского междуречья // Поселения. Среда, культура, социум: материалы тематической научной конференции. СПб: Изд-во СПбГУ, 1998. С. 59-61.

21. Герасимова Н.Г., Мазуркевич А.Н., Иванько Н.И. О возможностях фосфатного анализа при изучении культурного слоя // Поселения. Среда, культура, социум: материалы тематической научной конференции. СПб: Изд-во СПбГУ, 1998. С. 56-59.

22. Кулькова М.А., Полковникова М.Э., Мазуркевич А.Н. Опыт применения геохимии для реконструкции функциональных зон на поселениях каменного века // Материалы и исследования по археологии России и Беларуси. Комплексное исследование и синхронизация культур эпохи неолита - ранней бронзы Днепровско-Двинского региона. СПб: Инфинити, 2012. С. 22-45.

23. Мазуркевич А.Н. Опыт создания программы анализа распределения находок в культурном слое // Древности лесной зоны Восточной Европы. СПб., 1994. С. 12-13.

24. Мазуркевич А.Н., Полковникова М.Э., Короткевич Б.С., Кулькова М.А. Древности Верхнего Подвинья в исследованиях СЗАЭ // Г.Э. Отчетная археологическая сессия за 2000 год. СПб. 2001. С. 3-6.

25. Полковникова М.Э. Планиграфическая и «культурная» структура ранненеолитического поселения Сертея XIV // Древности Подвинья: исторический аспект. СПб. 2003. С. 99-106.

26. Мазуркевич А.Н., Короткевич Б.С., Полковникова М.Э., Кулькова М.А., Зайцева Г.И., Саблин М.В., Савельева Л.А. Исследования древностей Верхнего Подвинья Северо-Западной Археологической экспедицией Государственного Эрмитажа // Отчетная археологическая сессия за 2002 год // СПб., 2003. С. 3-10.

27. Кулькова М.А. Хронология ландшафтно-палеоклиматических событий и культурно-исторических процессов голоцене на территории Двинско-Ловатьского междуречья // Материалы и исследования по археологии России и Беларуси. Комплексное исследование и синхронизация культур эпохи неолита ранней бронзы Днепровско-Двинского региона. СПб: Инфинити, 2012. С. 64-87.

28. Зайцева Г.И., Кулькова М.А., Мазуркевич А.Н. Радиоуглеродная хронология неолита Днепро-Двинского междуречья // Археология озерных поселений IV-II тыс. до н.э. СПб., 2014. С. 65-85.

29. Мазуркевич А.Н. Отчет о работе Северо-Западной археологической экспедиции в 1992 году. НА ИА РАН. Ф. 1. Р. 1. № 17502. СПб., 1993.

30. Мазуркевич А.Н. Отчет о работе Северо-Западной археологической экспедиции в 1999 году. НА ИА РАН. Ф. 1. Р. 1. № 23391. СПб., 2000.

31. Мазуркевич А.Н. Отчет о работе Северо-Западной археологической экспедиции в 2002 году. НА ИА РАН. Ф. 1. Р. 1. Кн. 45. № 33863. СПб., 2003.

32. Мазуркевич А.Н. Отчет о работе Северо-Западной археологической экспедиции в 1997 году. НА ИА РАН. Ф. 1. Р. 1. № 21201. СПб., 1998.

33. Мазуркевич А.Н. Отчет о работе СевероЗападной археологической экспедиции в 2000 году. НА ИА РАН. Ф. 1. Р. 1. № 24298. СПб, 2001.

34. Dolukhanov P.M., Gey N.A., Miklyayev A.M., Mazurkewicz A.N. Rudnya-Serteya, a stratified dwellingsite in the upper Duna basin (A multidisciplinary research) // Fennoscandia archaeologica VI. 1989. P. 23-27.

35. Мазуркевич А.Н., Кулькова М.А., Полковникова М.Э., Савельева Л.А. Раннеолитические памятники Ловатско-Двинского междуречья // Тверской археологический сборник. Вып. 2. Тверь, 1996. С. 260-267.

36. Микляев А.М. Каменный - железный век в междуречье Западной Двины и Ловати // Петербургский археологический вестник. № 9. СПб. 1994. С. 7-39.

37. Мазуркевич А.Н., Долбунова Е.В., К Кулькова М.А. Древнейшие керамические традиции Восточной Европы // Российский археологический ежегодник. СПб: Университетский издательский консорциум, 2013. С 27-108.

38. Мазуркевич А.Н. Отчет о работе Северо-Западной археологической экспедиции в 1993 году. НА ИА РАН. Ф. 1. Р. 1. СПб., 1994.

39. Мазуркевич А.Н., Полковникова М.Э. Некоторые результаты исследований ранненеолитических памятников долины р. Сертейки (Велижский p-н, Смоленская обл.) // Материалы и исследования по археологии России и Беларуси. СПб., 2012. С. 110-127.

40. Raczky P. House-structures under change on the Great Hungarian Plain in earlier phases of the Neolithic // Homage to Milutin Garasanin // Belgrade, 2006. P. 379398.

41. Komber J. New aspects of the development of houses from the Mesolithic to the Viking Period in Nothern Europe // From huts to houses. Transformations of ancient societies // Stockholm, 2001. P. 203-210.

42. Ozdogan M. Transition from the round plan to rectangular - reconsidering the evidence of Cayonu // Neolithic and Chalcolithic Archaeology in Eurasia: Building Techniques and Spatial Organisation. BAR International Series 2097. Oxford, 2010. P. 29-34.

43. Akar E. From hut to citadel: the evolution of housing and settlement in prehistoric Anatolia as patterns of 
space and time // From huts to houses. Transformations of ancient societies // Stockholm. 2001. P. 11-21.

44. Stordeur D., Abbes F., Du PPNA au PPNB : mise en lumiere d'une phase de transition a Jerf el Ahmar (Syrie) // Bulletin de la Societe prehistorique française. T. 99, n3. 2002. P. 563-595.

45. Kobayashi T., Kaner S., \& Nakamura O. Jomon reflections. Forager life and culture in the prehistoric Japanese archipelago. Oxford: Oxbow Books, 2004. 256 p.

46. Борзунов В.А., Кирюшин Ю.Ф., Матющенко В.И. Поселения и жилища эпох камня и бронзы Зауралья и Западной Сибири // Памятники древней культуры Урала и Западной Сибири.//Екатеринбург, 1993. C. 4-45.

47. Thomas J. Mesolithic-Neolithic transitions in Britain: from essence to inhabitation // The MesolithicNeolithic Transition in Europe. London: British Academy, 2007. P. 423-439.

48. Kriiska A. The beginning of farming in the Eastern Baltic // The east European plain on the eve of agriculture. Oxford: Oxbow Books, 2009. C. 159-179.
49. Ozdogan M. A new look at the introduction of the Neolithic way of life in Southern Europe. Changing paradigms of the expansion of the Neolithic way of life // Documenta Praehistorica XLI. 2014. P. 33-49.

50. Nordqvist K. and Kriiska A. Towards Neolithisation. The Mesolithic-Neolithic transition in the central area of the eastern part of the Baltic Sea // Archaeology and History of the Baltic 8. 2015. P. 537-556.

51. Ozdogan M. The expantion of the neolithic way of life: What we know and what we do not know // How did farming reach Europe? Anatolian-European relations from the second half of the 7th through the first half of the 6th millennium Cal BC. Proceedings of the International Workshop. Istanbul, 20-22 May 2004. BYZAS 2. 2005. P. 13-27.

52. Mlekuz D. The Neolithic Year // The Oxford Handbook of Neolithic Europe. Oxford, 2014. P. 447-461.

53. Mlekuz D. Bodies, houses and gardens: rhythm analysis of Neolithic life-ways // Documenta Praehistorica XXXVII. 2010. P. 193-204.

\section{THE EARLIEST DWELLINGS OF THE STONE AGE IN SMOLENSK AND PSKOV REGIONS OF RUSSIA}

(C) 2016

\section{I.Yu. Khrustaleva, junior researcher of Eastern Europe and Siberia Archaeology Department} The State Hermitage Museum, Saint Petersburg (Russia)

Abstract. The following paper analyzes the ancient building traditions of the upper Dvina basin. The paper deals with the earliest dwellings in the region, found on the base layer of seasonal Stone Age settlements of the Smolensk and Pskov regions: Serteya 3-3 Serteya X, Serteya XIV, Rudnya Serteyskaya and settlement Uzmen. During the excavation, these materials were isolated in a single layer of Early Neolithic Serteyskaja culture. As a result of spatial analysis of the dwellings remains on the settlements Serteya X, Serteya XIV, and studying findings correlated with these structures, the existence of Mesolithic buildings were allocate and justified within this layer. An analysis of the plans and remains of structures revealed the features of the Mesolithic - Early Neolithic transition, manifested in dwellings form changing: the transition from round to oval and subrectangular in plan that also noted by the Stone Age archaeologists, not only for the territories of the forest zone. Such changes are unlikely to be random, and probably can be considered as Neolitization element, but these assumptions still require further research and evidence.

Keywords: Mesolithic; Early Neolithic; Serteyskaya Early Neolithic Culture; North-West Russia; Smolensk region; Pskov region; dwellings; the buildings; Neolithization; seasonal settlements; sites; settlements in the sandy sediments; the relative chronology.

УДК 902.903'12

\section{К ИЗУЧЕНИЮ РЫБОЛОВСТВА В ЭНЕОЛИТЕ ЛЕСОСТЕПНОГО ПОВОЛЖЬЯ (ПО МАТЕРИАЛАМ РАСКОПОК ПОСЕЛЕНИЯ ЛЕБЯЖИНКА VІ В 2013-2014 ГГ.)} (C) 2016

А.И. Королев, кандидат исторических наук, декан исторического факультета, доцент кафедры отечественной истории и археологии

А.А. Шалапинин, кандидат исторических наук, научный сотрудник научно-исследовательской части Самарский государственный социально-педагогический университет, Самара (Россия)

Е.Ю. Яниш, кандидат биологических наук, младший научный сотрудник отдела мониторинга и охраны животного мира Институт зоологии им. И.И. Шмальгаузена, Киев (Украина)

Аннотация. В статье рассматриваются орудия рыбного промысла и кости рыб поселения Лебяжинка VI лесостепного Поволжья эпохи энеолита в рамках комплексного исследования памятника. В заполнении котлованов жилищ выявлена керамика с «внутренним ребром», каменные, костяные орудия, кости животных, черепах, птиц и рыб. Особое значение поселения заключается в возможности изучать их как один комплекс. Целью данной статьи является анализ орудий лова и охоты на рыбу и костей рыб. К орудиям охоты относятся костяные гарпуны с одним, двумя и многими зубцами, расположенными по одной стороне. Костяные рыболовные крючки двух типов: цельные крючки-блесна и составные. Определены типологические особенности орудий лова, выполнены количественные, видовые, возрастные, размерные характеристики рыб. Основными были 